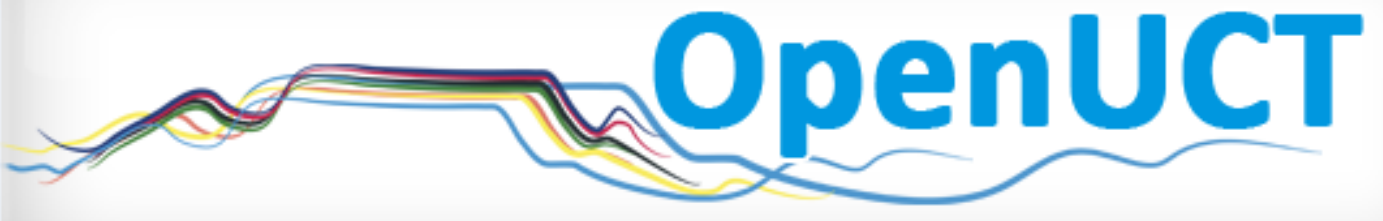

This is the author-approved manuscript version of a journal article published in:

Kapp, R. \& Bangeni, B. 2009. Positioning (in) the discipline: undergraduate students' negotiations of disciplinary discourses. Teaching in Higher Education. 14(6): 587-596. DOI: 10.1080/13562510903314988.

It is made available under the terms of agreement between the author and the journal, and in accordance with the University of Cape Town's Open Access Policy for the purposes of research, teaching and private study.

http://www.openuct.uct.ac.za/sites/default/files/UCTOpenAccessPolicy.pdf 


\title{
Positioning (in) the discipline: undergraduate students' negotiations of disciplinary discourses
}

\author{
Rochelle Kapp and Bongi Bangeni \\ Centre for Higher Education Development, University of Cape Town, Cape Town, \\ South Africa
}

\begin{abstract}
This paper is drawn from a longitudinal case study in which the authors have tracked the progress of 20 Social Science students over the course of their undergraduate degrees at a historically 'white' South African university. The students are all from disadvantaged educational backgrounds and/or speakers of English as a second language. The paper draws on post-structuralist and postcolonial theory to trace the process by which students position and reposition themselves in relation to disciplinary discourses over the course of their senior years. The students both absorb and resist the values of their disciplines. The authors argue that the process of writing in their disciplines is also a process of working out their own identities as they try to reconcile their home discourses with those of the institution and their peers, or in some cases, confirm or shed their home identities.
\end{abstract}

Keywords: discourses; identity; language; literacy; longitudinal study

... I simply reproduced what the tutors taught me about the subject, my writing was largely shaped by tutor's ideas, mine were scarce. [Sizwe, reflecting on first year]

The essay topic is structuring me. [Andrew, first-year reflection]

... I only participate when I am forced . . but sometimes I feel that I belong to a certain topic, like gender issues. I have strong views about gender and I participate in that.

[Belinda, first-year interview]

\section{Introduction}

The above quotations are drawn from a longitudinal case study (2002Á2004) in which we tracked the shifts in identity, as well as language and literacy practices and attitudes of 20 Social Science students over the course of their undergraduate degrees at a historically 'white', 1 South African university. Aside from one Chinese student, the participants in our study are all 'black' and from disadvantaged educational backgrounds and/or speakers of English as a second language. They were (with the exception of one student) the first in their families, sometimes the first in their communities, to attend university. 
They were taught by us in their first year in an academic literacy course designed for students considered academically 'at risk' on the basis of their performance on an entrance test and their school-leaving results.

In 2002, when our participants first arrived, $39 \%$ of the university's undergraduate student population consisted of 'black' South Africans, and $82 \%$ of academic staff were 'white'. Many of the dominant institutional academic and cultural practices are still 'white', English, middle-class and male (even Oxbridge) in character. First-generation 'black' students are entering the institution in a moment of societal transition that offers them previously unheard of possibilities in terms of upward mobility. They are sought after by the institution because of the low number of 'black' applicants. However, because of their relatively low matriculation results, they are often not accepted into their chosen field of study. The quotations above provide some insight into their initial feelings of being overwhelmed, of ambivalence and of alienation as students attempted to negotiate their way into the discourses of the institution. Nevertheless, all 20 of these students graduated, and nine continued to post-graduate study. Our research has attempted to trace each student's unique journey through the institution, showing the uneven processes through which they recast these initial feelings and repositioned themselves in relation to academic discourse.

In two papers (Bangeni and Kapp 2006; Kapp and Bangeni 2005) on students' first-year writing, we drew on post-structuralist and post-colonial theorists to describe the experiences of our research participants who, as the first of their generation in a new political dispensation, cross borders into new terrain with accepted ways of 'saying-doing-being-valuing-believing', that is, 'discourses' (Gee $1990,142)$. To become accepted members of dominant discourses, such as academic disciplines, individuals are required to act, think, speak and write within their ideological frameworks. For 'black' South African students from working-class communities who are not fully proficient in English, and who come from printimpoverished home backgrounds and schools which have not facilitated close, critical engagement with texts (Christie 2008; Kapp 2004; Slonimsky and Shalem 2004), this poses particular difficulties. Within the institution, students' home discourses are constructed as a problem that has to be fixed through the provision of courses (Rose 1990).

What is hidden from the institution is that because improving language and academic writing skills becomes inextricably tied to becoming proficient in the dominant discourse, students often have to deal with challenging tensions around identity. For example, the discourses of the Social Sciences often clash with home discourses. For the students, the desire to attain access to the discourses of the former oppressor (as well as access to the metropole and its culture, made possible by South Africa's re-entry into global markets) is modulated by insecurity about ability, anger towards the former oppressor and by the desire to maintain social and cultural solidarity with the discourses of their families and communities at home. In Bhabha's $(1994,112)$ terms, 'the colonial hybrid is the articulation of the ambivalent space where the rite of power is enacted on the site of desire, making its objects at once disciplinary and disseminatory ... ' The degree to which students reconstruct who they are is regulated by their motivation to 'invest' (Norton 2000, 10Á11) in the new discourses and also by the extent to which they are able to access the material, linguistic, social and cultural resources that are valued within dominant discourses. 
We used Clark and Ivanic's (1997) theory on writer identity to trace students"v shifting representation of self Á the conflict between what Clark and Ivanic (1997," 134) refer to as 'their former selves and their becoming-selves'. They identify three (often overlapping) aspects of writer identity, which they describe as the 'discoursal' self, the 'authorial' self and the 'autobiographical' self (Clark and Ivanic 1997, 136Á 52). The discoursal self refers to a writer's awareness of the discipline for which they are writing. The authorial self refers to the writer's authority, the extent to which writers take ownership of their writing and the autobiographical self refers to the extent to which writers draw on their personal histories.

In their early essays, students asserted a strong 'authorial' presence in the text, albeit in emphatic or conversational tones not conventionally considered appropriate by the discourse. They drew on their home discourses to write about their religious beliefs, their connections to the ancestors and their ethnic identities. They wrote of their personal experiences of trauma and violence. Students drew on personal biography irrespective of whether or not the discipline sanctioned them to do so. However, when they found that their own 'voices'/experiences and language were not valued by markers, they yielded authorial presence in favour of an uncritical mimicking of the discourse which enabled them to pass (see also Paxton 2003, for similar findings).

At the end of an article describing this process (Bangeni and Kapp 2006), we asked, whether students would retain this subject position and whether they would see the value of asserting authorial presence and drawing on their own experiences in their senior years. In this paper, we attempt to answer that question by examining how students position themselves in relation to their disciplines and by analysing how they position themselves in their writing.

Underlying our research question is our notion of what constitutes academic literacy in the Social Sciences. We believe that students do need to become fluent in the discourses of the Social Sciences and that this process takes time. However, acquiring fluency need not entail uncritical reproduction and the discourse need not be over-determining. The university has a stated mission to achieve transformation within the institution and to make a contribution to transformation and development within South Africa. Such a task requires a nuanced understanding of diversity which has not been possible in a divided South Africa. In such a context, as Thesen (1997) has argued, students' experiences of workingclass township and rural life constitute an important resource and have the potential to contribute to new knowledge in a time that the academy is itself trying to come to terms with its identity in a context of unprecedented societal change and transition.

\section{Brief methodological outline}

Our data consist of four individual semi-structured interviews with each student, two focus group interviews, essays from a range of each student's courses over three years and reflection papers on their writing, produced by the students towards the end of their undergraduate studies. Our interviews were semi-structured, in order to facilitate comparison within each student's corpus over time, as well as comparison between students. However, we always also asked individual questions based on prior interviews and on our analyses of students' essays. We focussed on questions 
related to their approaches to writing; their language attitudes and practices; their relationship to the environment (both to their peers and their lecturers); and their relationship to their home communities.

The reflection papers asked students to draw on their corpus of undergraduate essays in order to analyse the changes in their writing and ideas over three years. We asked about their relationship to their disciplines. We also asked about their writing strategies and tried to access their notions of good writing.

We have used these different sets of data to try to distinguish 'between how people think they ought to behave, how they say they behave and how they are observed to behave' (Le Page and Tabouret-Keller 1985, 207). In this way we are able to trace their shifts in literacy practices in relation to identity Á how they position and reposition themselves in relation to disciplinary discourses over the course of their senior years. In this article, we draw primarily on their reflection papers to compare the statements they make with the identities presented in their interviews and in their writing.

\section{Shifting approaches to writing}

Our students had had very little experience of extended writing prior to entry into university. Both in the early interviews and in their reflection papers (in their third year), students spoke of how their first-year writing was driven by fear of failure and the instrumental desire and pressure to pass. On reflection, they observed that their early writing was characterised by reproduction, in Sizwe's terms, 'my own ideas were scarce'. Almost uniformly, the reflection papers expressed shock at how badly they wrote in first year. Students seemed particularly perturbed by the lack of evidence in their essays, the limitation of their perspective and their perceived inability to analyse. They saw none of the early promise which we described in our analysis of their first-year writing (Bangeni and Kapp 2006).

The students' reflections provided evidence that they had developed a high degree of meta-awareness about their writing. Sisanda described how her approach to argument construction shifted over the course of three years:

... First year to me essays were about reporting what I have learnt which was obviously not a good idea ... Second year, to make things easier I told myself I will read and either support or critique the author in addition to reading ... In constructing my arguments [in third year], not only do I discuss and support/critique the authors, I compare and differentiate their views to build on my own opinions and views that I include in the paper as some point of departure or recommendation ...

This meta-cognition was also evident in the coherent, well-researched argumentation which seemed to characterise students' senior essays. In general, the students started off achieving mid to upper thirds (55Á59\%) in first year and progressed to lower seconds (mid-60s and above) in second and third year. They very seldom achieved upper-second (70Á74\%) and first-class passes.

\section{Positioning in the discipline}

Students' reflection papers and interviews in their senior years revealed an 'investment' (Norton 2000) in their disciplines which was certainly not evident 
earlier. Whilst not fully comfortable in their disciplines, students nevertheless expressed a growing allegiance to the values and culture of the discipline. This marked shift in attitude was evident in Andrew who, in his first year, spoke of being ideologically constrained by his Psychology first-year essays: 'The essay topic is structuring me'. In an unsolicited preamble to his reflection paper in his final year, Andrew wrote:

... I am in an academic discourse where it is required of one to act/or to be the discipline, this is what I have come to realize over these past years. It is one thing to be in the discipline and another 'to be' the discipline. And each day I find more and more evidence within myself that I am at that point where I moved from being in my discipline, to where I am my discipline. This is evident in my speech, thought, and ways I approach certain things, whether in academic or formal setting.

Andrew's analysis, as well as the language in which it is expressed, reflected a growing awareness that he was not only learning the skills and content of the discipline, but was also entering into new subjectivities (see Herrington and Curtis 2000; Johns 1997). In Gee's (1990, xviii) terms:

[t]here is no such thing as 'reading' or 'writing', only reading and writing something (a text of a certain type) in a certain way with certain values while at least appearing to think and feel in certain ways. We read and write only within a Discourse ... [emphasis in the original]

Other students expressed this shift in more concrete terms than Andrew. For example, in stark contrast to his first interview when he spoke of his distaste for 'this critical analysis thing', in his third year David wrote about how being in Social Anthropology had shifted his mindset from a pursuit of wealth: 'I realised that everything wasn't as clear cut as I thought. I was exposed to the negative impact of what getting rich meant'. In his final interview he spoke of how Sociology had helped him be less judgmental of his community: 'I try to understand them [members of my community] from their own context'. Similarly, in her first year Babalwa expressed extreme frustration because in Philosophy 'you keep on debating because there's no answer ... They say they don't look at the outcome, but in a way you are because you are using education as a means to go'. By contrast, in her reflection paper, she wrote:

I have grown to realize that what I have been taught about God, females and males, the world is not necessarily what it is and that what I believe in is not necessarily true or wrong Á not everything is black and white ... I have learnt that human beings are not passive; they question things, its roots and how things become universally accepted (the norm).

A number of students described their 'investment' in a particular discipline and consequent shift in perspective. Their reflections showed awareness of disciplinary differences:

Since starting Gender Studies in second year, I think my ideas about what is and was academically correct changed tremendously. Your personal ideas and interpretations are in no sense inferior because that's what you think. Gender Studies also gave me the opportunity to write about topics that would be frowned on in other faculties. Besides this writing freedom, I think the wide variety of courses that I have studied has also influenced my ideas because of its diversity. (Belinda) 
Students' growing allegiance to their disciplines is particularly interesting given their early statements and also because almost each one of them had had to settle for second choice after being refused entry into their chosen field on the basis of their school-leaving results. Their strong 'investment' in their disciplines came at a time when they felt increasingly alienated from their home environments and when they used English more and more often in their informal interactions (see Bangeni and Kapp 2005, 2007, for more detailed description). It seems that the longer they spent in the institution, the more the ideology of the discourse came to seem not only acceptable, but also 'natural', and in some cases, personally liberating. Now put in Gee's (1990) terms, they have been colonised by the discourse. In Althusser's (1971) terms, ideology has interpellated them as subjects.

However, we want to suggest that the relationship is more complex, less reifying and linear than either of these descriptions. Our students both absorbed and resisted the new discourses and inhabited multiple subject positions as they attempted to reconcile conflicting home and institutional discourse practices (see Reay 2001, for a similar observation). The process that Belinda described in Gender Studies was actually an affirming rather than transforming process because she had entered the academy with an (unconscious) feminist stance strongly informed by her life experiences. Her time in Gender Studies provided her with the permission and the conceptual and linguistic vocabulary to frame, develop and express this consciousness.

On the other hand, despite women students like Babalwa saying that academic discourse had taught them to question patriarchy, in their interviews they spoke of how they resumed passive, gendered roles in order to fit in when they went home. Whilst most students described their growing critique of materialism, their everyday practices suggested increasing levels of consumerism. These contradictions reflected students' ambivalence as they attempted to respond to multiple, and often conflicting, expectations of who they were and who they should be in the process of negotiating the social boundaries within the institution and between the institution and home.

A significant marker of the changing relationship to their disciplines is the way in which many students foregrounded their growing awareness of the significance of 'audience' in their work. Andrew spoke of his struggles to achieve a measure of 'objectivity' in areas where 'we are dealing with issues that are close and mostly subjectively motivated . . . I find myself more and more in a situation where I have to produce a written piece where I am unable to separate myself from what I produce'. He wrote that he sees himself as part of the audience 'although academics are assumed to be the predominant audience'. Belinda wrote about learning about 'audience' when she wrote in a feminist tone considered inappropriate by a lecturer in the Department of Classics. She wrote of being most excited by essays where she could express emotion and draw on personal experience. Similarly, David wrote about audience in terms of distance: 'I have a clearer sense of audience in mind when I am more distanced', but also in terms of emotion: 'I'm a good writer if I feel passionately'. Whilst students' comments reflect their personal 'investment', they are also evidence of their recognition that Social Science writing mainly requires low affect. They had had to learn to separate themselves to adjust to the measured tone of the academy and express emotion only when sanctioned to do so. 


\title{
Positioning in the text
}

The type of writing that students were required to write in their senior years can roughly be divided into two categories: (1) reflective writing which required them either to use theory to reflect on everyday/personal experience or to interview respondents and use theory to analyse their responses; and (2) the more conventional expository essays, which, based on secondary sources, required students to provide explanations for causes and consequences, to critically analyse quotations or to engage in comparative critique.2

Students were very seldom asked to engage in reflective writing in their senior years, and interestingly, even when they were highly enthusiastic and excited about the opportunity to reflect on personal experience and to write (in Belinda's words), 'about topics that angered you, made you cry and frustrated you at the same time', their writing reflected real difficulty with the genre. The difficulties manifested at the level of form Á expression of emotion, explicitness, structure Á and in terms of content, in particular using theory to interpret and explain. Markers themselves seemed to struggle to provide feedback, varying between commending the personal insights/sharing and (in one case) suggesting therapy on the one hand, and on the other, enjoining students to use a 'broader vocabulary' or to avoid 'and then' narrative styles of writing.

Some of these issues were evident in David's third year tutorial assignment for an Anthropology course (on conceptions of culture), which asked 'What do YOU think of social diversity' [emphasis in the title]. David and a fellow student interviewed university students on the issue and reflected on the interview in separate essays. Describing an interview with an unforthcoming 'coloured', woman, he wrote:

\begin{abstract}
... she said that 'black culture' was about 'Ubuntu', about giving and sharing whereas other cultures were more competitive. Another stereotypical statement slipping off Kelly's tongue as the contradictions in her thoughts became more evident. She defined culture as the whole of one's morals; upbringing and traditions practised such as 'the norms one follows'. Her culture was described as 'Christian and South African'.
\end{abstract}

Kelly started to drift off and lose interest ...

The casual narrative style and the forthright assertions and judgement 'stereotypical statement', 'contradictions in her thoughts' and 'Kelly started to drift off' in this essay stand in sharp contrast to his response to a more conventional topic from the same course entitled 'Redefining culture? Or dispensing with the term?'. David wrote:

... Ngugi's (1993) main argument is that language is the sole carrier of people's culture and history and that if their language is systematically suppressed, so too will their culture, history and values be suppressed. This would be the case if language as an explicit form of communication determined what people know and how they could learn these things. As Bloch points out though, it is taken as a given fact 'that culture is thought and transmitted as a text through language (only), or that culture is ultimately "language like", consisting of linked linear propositions' (Bloch 1991, 184) . . .

We used Hyland's (2005) work on writer identity to analyse this essay. Hyland (2005, 180 ) writes about how academic writers generally use a delicate balance of hedging (expressions of caution) and boosters (expressions of certainty/authority) in order to convince readers of the validity of their argument. He writes: 
Both boosters and hedges represent a writer's response to the potential viewpoints of readers and an acknowledgement of disciplinary norms of appropriate argument. They balance objective information, subjective evaluation and interpersonal negotiation, and this can be a powerful factor in gaining acceptance for claims.

From the second extract, we can see that David has learnt to argue within the frame of the norms and values of Social Science argument, carefully balancing hedging with boosting of his claims. He engages in precise, extended and layered definition of concepts and classification using a range of sources. Compared to the first essay, the writing is explicit, formal and distanced. He uses careful modality: 'this would be the case if ... ' rather than the bold assertions of his early writing. Even when certainty is expressed, it is articulated via authority 'As Bloch points out, it is taken as a given fact'. The passive voice embedded within the statement 'it is taken' expresses the writer's caution and deference.

David's own 'authorial' presence (Clark and Ivanic 1997, 136) is carefully" martialled through the voices of others, through comparison of sources, using one source to critique another, as in 'It is cognitive scientists who argue ... as Ngugi would have us believe ...' In contrast to the first extract, he uses low inference vocabulary, there are very few adjectives and adverbs that mark attitude and the personal pronoun is absent. The only direct statements of point of view are in his introduction and conclusion where he states and elaborates on his thesis that 'Ngugi's (1993) emphasis on language as the main cultural tool is somewhat overstated'. In Martin's (2000) terms David expresses clear judgement, but low affect. His success is evident in his achievement of a first for this essay.

The strong thesis in the 'Ngugi' essay was fairly unusual for David and for our data corpus as a whole. In general, essays reflected extreme deference and heavy reliance on the content and authority of secondary sources. Although students' 'authorial' voices are present, they are effaced, often appearing only towards the end, as in Belinda's Gender and History essay, where she took a strong stance, writing with conviction and authority and using the personal pronoun for the first time in the conclusion:

\begin{abstract}
I think the reason why the mobility of Basotho women was a threat to Basotho paternalist and white patriarchs was that the whole situation symbolized a loss of control. A loss of control over their women and their sexuality led to a decrease in paternal power and a diminishing of men's power in the gender order caused the paternalist to feel threatened.
\end{abstract}

Students' deference seemed to play a large part in holding them back from achieving upper-second and first-class passes. For the most part, the primary feedback on their writing came in the form of ratings on marking grids developed by departments. Our participants tended to score average or above-average marks on content categories (relevance to the essay question, grasp of core concepts, comprehensiveness, etc.), as well as in the areas of coherence and planning. However, they were judged 'weak' in areas related to 'creativity, originality, critique, personal insights', etc. In students' reflections, they accounted for their failures to achieve higher marks in terms of their struggles with English, but although 'lack of precision in language' was often marked, this seemed to be a fairly minor, and sometimes non-existent, category in most departments. 
Students' deference to authority reflected an insecurity that was also visible in their tendency to consult tutors rather than lecturers and in their hesitation to participate in class. Andrew, who wrote in his reflection paper 'I am the discipline', also talks in his interview two months earlier of his insecurity about participating in class. Drawing on the discourse of Psychology, he names it 'the fear of the child':

\begin{abstract}
... this soft guy if I may put it, is still there hey, it is still there, and I was trying to change and . . . but it is still a barrier . . . It becomes more visible also when I find myself in a position to say something ... You are eager to speak, it just takes me a moment and I will talk and in the same time it will come to my mind . . . you are talking in front of people now and I would start shaking and words won't come out of my mouth and I'll have this expression on my face and I will turn red.
\end{abstract}

\title{
Conclusion
}

Rather stereotypically, our answer to whether students do manage to assert authorial presence in their senior writing, is a typical 'hedge': they do to some extent. What is clear to us is that students invest in their disciplines Á they are no longer just mimicking. They both absorb and resist the values of their disciplines, though Belinda's Classics' essay is one of the few occasions when this struggle is visible in their writing. Students show awareness of, but do not necessarily learn to walk the tightrope between hedging and boosting, between emotion and distance. Just as they do not fully become part of the institution, they very seldom articulate a strong presence in the discourse.

Whilst on the surface, these students are very successful in the eyes of the institution and of their families, the fact that they achieved lower second marks rather than upper seconds or firsts, prevented them from being accepted into the Honours degrees of their choice, just as they were prevented from entering the undergraduate degrees of their first choice. A close analysis of their trajectory through the institution shows that all along they have had to re-adjust, adapt, reposition themselves in order to negotiate their identities within the discipline, within the institution and at home.

Universities have become quite good at providing the necessary academic structures to help first-year students. However, we still have a long way to go in terms of recognising and providing support for both the academic and affective dimensions of their transition and in terms of engaging critically with the effects of our own discourses. The academy also has a long way to go in terms of finding ways to enrich the Social Science debate by drawing on the knowledge and experiences that students bring with them from their home environments.

\section{Acknowledgements}

We are very grateful to Profs Mugsy Spiegel and Kelwyn Sole for their comments on a draft of this article. This material is based upon work supported by the National Research Foundation (under grant number 2054167) and the University of Cape Town. Any opinions, findings and conclusions or recommendations expressed in this material are those of the authors, and therefore, the NRF does not accept any liability in regard thereto. 


\section{Notes}

1. It is impossible to contextualise fully the imbrications of South African language and educational backgrounds without using the Apartheid-era racial categorisation. However, to signify our own beliefs that these categories are to some degree at least, artificially constructed, we will use quotation marks. In this paper we use the category 'black' inclusively to refer to 'African', 'Coloured' and 'Indian' students.

2. We have not analysed students' major research projects in which many were required to engage in primary research.

\section{References}

Althusser, L. 1971. Lenin and philosophy and other essays. Trans. Ben Brewster. London: New Left Books.

Bangeni, B., and R. Kapp. 2005. Identities in transition: Shifting conceptions of home by black South African university students. African Studies Review 48, no. 3: 1 Á19.

Bangeni, B., and R. Kapp. 2006. 'I want to write about the Dalai Lama without being penalized?': Literacies in transition. In Academic literacy and languages of change, ed. L. Thesen and E. Van Pletzen, 67Á83. London: Continuum Press.

Bangeni, B., and R. Kapp. 2007. Shifting language attitudes in a linguistically diverse learning environment. Journal of Multilingual and Multicultural Development 28, no. 4: 253Á70.

Bhabha, H. 1994. The location of culture. London: Routledge.

Christie, P. 2008. Changing schools in South Africa: Opening the doors of learning. Johannesburg, South Africa: Heinemann.

Clark, R., and R. Ivanic. 1997. The politics of writing. London: Routledge."

Gee, J. 1990. Social linguistics and literacies: Ideology in discourses. London: Falmer Press.

Herrington, A., and M. Curtis. 2000. Persons in process: Four stories of writing and personal development in college. Urbana, IL: National Council of Teachers of English.

Hyland, K. 2005. Stance and engagement: A model of interaction in academic discourse. Discourse Studies 7: 173Á92.

Johns, A. 1997. Text, role and context: Developing academic literacies. Cambridge, MA: Cambridge University Press.

Kapp, R. 2004. 'Reading on the line': An analysis of literacy practices in ESL classes in a South African township school. Language and Education 8, no. 3: 246 Á63.

Kapp, R., and B. Bangeni. 2005. 'I was just never exposed to this argument thing': Using a genre approach for teaching academic literacy. In Genre across the curriculum, ed. C. Moran and A. Herrington, 253Á70. Logan, UT: Utah University Press.

Le Page, R., and A. Tabouret-Keller. 1985. Acts of identity: Creole-based approaches to language and identity. Cambridge, MA: Cambridge University Press.

Martin, G. 2000. Beyond exchange: Appraisal systems in English. In Evaluation in text, ed. S. Hunston and G. Thompson, 142A75. Oxford: Oxford University Press.

Norton, B. 2000. Identity and language learning: Gender, ethnicity and educational language. London: Longman.

Paxton, M. 2003. Developing academic literacy in Economics in a South African university. Literacy and Numeracy Studies 12: 1 Á14.

Reay, D. 2001. Finding or losing yourself ? Working-class relationships to education. Journal of Education Policy 16, no. 4: 333Á46.

Rose, M. 1990. Lives on the boundary. New York: Penguin.

Slonimsky, L., and Y. Shalem. 2004. Pedagogic responsiveness for academic depth. In Curriculum responsiveness: Case studies in higher education, ed. H. Griesel, 81Á104. Pretoria, South Africa: SAUVCA.

Thesen, L. 1997. Voices, discourses and transition: In search of new categories in EAP. Tesol Quarterly 31: 487Á511. 